\title{
The Effect of Nursing Support on Drug Compliance in Inflammatory Bowel Diseases
}

\author{
Duygu Akbaş Uysal ${ }^{1 *}$ and Elif Ünsal Avdal ${ }^{2}$ \\ ${ }^{1}$ S.B.U. Bozyaka Training and Research Hospital, Burn Treatment Center, Specialist Nurse, İzmir, Turkey \\ ${ }^{2}$ İzmir Kâtip Çelebi University Faculty of Health Sciences Internal Diseases Nursing AD, Turkey
}

${ }^{\star}$ Corresponding author: Duygu Akbaş Uysal, Bozyaka Training and Research Hospital, Burn Treatment Center, Specialist Nurse İzmir, Bahar, Saim Çıkrıkçı Cd. No:59, 35170 Karabağlar/İzmir, Turkey; Email: duygu_akbas55@hotmil.com

Received: September 09, 2021; Accepted: September 15, 2021; Published: September 23, 2021

\begin{abstract}
Background: The main goal of the treatment of inflammatory bowel disease (IBD) is to achieve complete and permanent remission of the disease. A multidisciplinary team approach is also required to make the remission period long-term. IBD nursing in Turkey, Although these patients have begun a new specialization has been made about the pursuit of drug administration, did not find any work. It is thought that this study will provide a wellorganized nursing counseling for IBD patients and support patients in drug management.
\end{abstract}

Objectives: To examine the effect of nurse support on drug compliance in individuals with inflammatory bowel disease.

Method: After selecting the patients who are suitable for the sampling criteria included in the study, the study group was determined, and the patient information form and drug compliance information assessment form were administered to the individuals in the study group as a pre-test (month 0). The information included in the IBD Medical Education Booklet was given by the nurse twice a month in every 15 days on days suitable for the patients in the study group. One month after the training, the patient drug compliance assessment form was applied to the study group again and the scores of the group were analyzed by the nurse.

Results: The average age of the patients is 41.37 years, $53.3 \%$ female, $36.67 \%$ secondary school graduate and $66.67 \%$ married.

Post-training scores of the patients participating in the study increased. It was determined that the drug compliance of individuals with IBD who received nurse support for all other demographic features, except for patients with a maximum disease duration of 2 years, was high.

Conclusion: In this study, it was observed that nurse support given to individuals with IBD in drug management increased the effectiveness of drug use. Keywords: Inflammatory bowel disease, Inflammatory bowel disease nursing, Nurse support, Drug compliance

\section{Introduction}

Inflammatory Bowel Diseases (IBD) is a disease with chronic remission and exacerbations. IBD usually occurs during adolescence or young adulthood, and the etiology of the disease is still unknown $[1,2]$.

There are two types of inflammatory bowel disease, namely ulcerative colitis (UC), which is the continuous involvement of the colon; and crohn disease $(\mathrm{CH})$, which intermittently replaces any part of the gastrointestinal tract from mouth to anus [1-4]. Ulcerative colitis is a bowel disease that is limited to the rectum and colon, has continuous inflammation in the mucosa and generally presents rectal bleeding symptom $[1,2] . \mathrm{CH}$ is the most common disease occurring in the ileo-cecal region and then in the colon. Unlike ulcerative colitis, inflammation of the crohn is intermittent and appears as skipped lesions. Although the symptoms vary depending on the location of the disease, the most common symptom is abdominal pain $[1,2]$. The main goal in the treatment and maintenance of inflammatory bowel disease is to provide complete and permanent remission of the disease $[3,4]$. In the selection of pharmacological treatment method to be used for the targeted remission period, factors such as the location, intensity and disease activation time of the inflamed area are considered; the choice of a suitable oral, subcutaneous or parenteral drug is decided by healthcare professionals $[2,5]$. It is expected that the nurse will be included in this decision $[1,6]$. Drug groups generally applied in drug treatment; 5-aminosalicylic acid (5-ASA) are glucocorticoids and immunosuppressants [6-8]. With the introduction of biological agents in the last few years, progress has been made in the treatment of IBD and there is a need for more nurse support [6-8]. A multidisciplinary team approach is required to make the remission period, which is the main target of the treatment, long-term and to minimize the discomfort caused by the drug side effects [6-10]. In addition, the absence of a specific etiological factor in inflammatory bowel disease caused the lack of protective treatment methods [10-14]. Therefore, comprehensive management of these patients in the clinic should be provided by IBD nurses [10-14]. 


\section{Purpose of the Research}

The research aims to examine the effect of nurse support on drug compliance in individuals with inflammatory bowel disease.

\section{Material and Methods}

\section{Type of the Study}

The research is a semi-experimental (single-group pretestposttest), prospective, relational type research.

\section{Place of the Research}

The research was carried out in İzmir Katip Çelebi University Atatürk Training and Research Hospital Gastroenterology Unit between 11 September 2017 and 01 January 2018.

\section{Research Universe/Sample}

The population of the study was taken between 11 September 2017 and 01 January 2018, individuals with IBH who were hospitalized in İzmir Katip Çelebi University Atatürk Training and Research Hospital Gastroenterology Department, and a diagnosis of inflammatory bowel disease admitted to the IBD outpatient clinic at İzmir Katip Çelebi University Atatürk Training and Research Hospital formed individuals with IBD. Between the dates specified in this universe, $\mathrm{n}$; 30 individuals with IBD, who comply with the criteria of being included in the study, accessible and volunteering, served as the sample of the study.

\section{Data Collection Tools-Validity and Reliability Information}

In this study, a Patient Information Form with IBD, a Drug Compliance Information Assessment Form for patients diagnosed with IBD, and a Pharmaceutical Management Booklet for patients with IBD were prepared by the researcher with the opinion of experts to collect data. 9 questions examining the demographic characteristics of the patient such as age, gender, education level in the IBD information form; there are 5 questions about how long the disease has been present, and periods of exacerbation. There are 10 closed-ended questions in the IBD drug compliance assessment form. The questions in the form were evaluated as correct (1), incorrect/unanswered (0). A raw score of 0-10 was obtained for individuals with IBD and scores were evaluated over 100 for ease of interpretation. The fact that the total score obtained from the drug compliance information assessment form in patients diagnosed with inflammatory bowel disease was high, showed that the person with IBD had a high knowledge of their drugs. This form was applied to patients with IBD twice as pre-test (before training) and post-test (after training) and training efficiency was evaluated.

\section{Inflammatory Bowel Disease Medical Management Information Booklet}

In the booklet, there are three main topics: Medical Management of Inflammatory Bowel Disease, Purpose of IBD Medical Treatment, Drugs Used in Treatment (5-ASA agents, Sulfasalazine, Corticosteroids, Immunomodulators, Antibiotics) Elements to be Considered in General Medical Treatment of IBD.

\section{Action/Intervention}

Before starting the application, the patients were diagnosed in terms of sociodemographic characteristics and drug compliance information, and the training program was applied after the diagnosis was made (mont 0 ). The main material used in the training program is the IBD Medical Education Booklet prepared by the researcher in line with the current literature. The information included in the IBD Medical Education Booklet was given by the nurse twice a month in every 15 days on days suitable for the patients in the study group. One month after the training, the patient drug compliance assessment form was applied to the study group again and the scores of the group were analyzed by the nurse. The training was given to the patients in a comfortable, quiet, appropriate light, temperature and furniture arrangement in the outpatient clinic environment, protecting the privacy of the patient. The nurse who teaches is doing a master's degree and has attended trainings on the subject. The trainings were given using a booklet and a slide show prepared on the subject. During the training, patients were encouraged to ask questions. After the training sessions, noncompliance with patients who did not comply was discussed and individual goals were determined and achievement of targets.

\section{Evaluation of the Data}

SPSS (Statistical Package for the Social Sciences) 23 program was used to evaluate the findings obtained in the study. While evaluating the study data, Wilcoxon signed rank test was used as a nonparametric statistical test since it does not show normal distribution for demographic properties. Median, one of the descriptive statistical methods, was used while evaluating the study data. Descriptive characteristics of individuals with IBD included in the study were calculated as a percentage. Drug information score averages of patients with IBD were evaluated with pre-test, post-test, appropriate analysis.

\section{Results}

Thirty patients treated at our center between 11 September 2017 and 01 January 2018 were included in the study. The characteristics of the patients who received training within the scope of the study are shown in Table 1. The average age of the patients is 41.37 years, $53.3 \%$ female, $36.67 \%$ secondary school graduate and $66.67 \%$ married. $90 \%$ of the patients stated that they experienced changes in their normal life due to the disease.

According to the data obtained from Table 2, the ages of individuals with IBD participating in the study vary between 23 and 60 and the average age is 41.37 .

According to Table 3, patients are among the changes due to the disease; it is most disturbed by changes in the excretory habit. And in the vast majority of patients, working life has changed.

According to Table 4, the lowest score in the first test is 10, while the highest score is 80 . In the last test, it can be seen that the scores received vary between 40 and 100. In addition, although the average of the scores obtained in the pre-test was 49.67 , the average of the scores from the post-test was 72.67 . This result shows that nurse support increases the effect of drug compliance. 
Table 1: Sociodemographic Characteristics of the Participants.

\begin{tabular}{|c|c|c|c|}
\hline & & $\mathbf{n}$ & $\%$ \\
\hline \multirow{3}{*}{ Gender } & Female & 14 & 46.67 \\
\hline & Male & 16 & 53.33 \\
\hline & Total & 30 & 100 \\
\hline \multirow{4}{*}{ Marital Status } & Married & 20 & 66.67 \\
\hline & Single & 9 & 30 \\
\hline & Divorced & 1 & 3,33 \\
\hline & Total & 30 & 100 \\
\hline \multirow{5}{*}{ Educational Status } & Literature & 1 & 3,33 \\
\hline & Primary Education & 8 & 26,67 \\
\hline & Secondary education & 11 & 36,67 \\
\hline & High education & 10 & 33,33 \\
\hline & Total & 30 & 100 \\
\hline \multirow{3}{*}{ Work Status } & Working & 16 & 53.33 \\
\hline & Not working & 14 & 46.67 \\
\hline & Total & 30 & 100 \\
\hline \multirow{4}{*}{ Economic Situation } & Over Income Expense & 1 & 3,33 \\
\hline & Income and Expense Equal & 21 & 70,00 \\
\hline & Income Less Than Expense & 8 & 26,67 \\
\hline & Total & 30 & 100 \\
\hline \multirow{3}{*}{ There is Social Security } & Yes & 26 & 86.67 \\
\hline & No & 4 & 13.33 \\
\hline & Total & 30 & 100 \\
\hline \multirow{3}{*}{$\begin{array}{l}\text { Has your normal life changed due } \\
\text { to your illness? }\end{array}$} & Yes & 27 & 90 \\
\hline & No & 3 & 10 \\
\hline & Total & 30 & 100 \\
\hline
\end{tabular}

Table 2: Questions marked with multiple answers about the disease.

\begin{tabular}{|l|c|c|c|c|c|}
\hline & $\mathbf{N}$ & Minimum & Maximum & Mean & Std. Deviation \\
\hline Age & 30 & 23 & 60 & 41,37 & 11,226 \\
\hline
\end{tabular}

Table 3: Descriptive Statistics of the Age Variable.

\begin{tabular}{|l|l|c|c|}
\hline & & $\mathbf{n}$ & $\mathbf{\%}$ \\
\hline \multirow{4}{*}{$\begin{array}{l}\text { Which of the changes cause } \\
\text { by the disease bothers you the } \\
\text { most? }\end{array}$} & Changes in eating and drinking habits & 10 & 20.83 \\
\cline { 2 - 4 } & Changes in daily activities & 11 & 22.92 \\
\cline { 2 - 4 } & Changes in excretion & 22 & 45.83 \\
\cline { 2 - 4 } & Changes to your skin & 4 & 8.34 \\
\cline { 2 - 4 } & Changes in sexual functions & 1 & 2.08 \\
\hline \multirow{3}{*}{$\begin{array}{l}\text { Which or which changes } \\
\text { occurred? }\end{array}$} & In family relationships & 9 & 22.22 \\
\cline { 2 - 4 } & In working life & 9 & 33.33 \\
\cline { 2 - 5 } & In interpersonal relations & 4 & 14.82 \\
\cline { 2 - 4 } & All & 29.63 \\
\hline
\end{tabular}

IBD nurse met with patients twice to provide training. It was observed that IBD patients who received nurse support for all demographic characteristics, except for patients with a maximum duration of 2 years, had a high effect on drug compliance (Table 5).
Table 4: Investigation of Drug Compliance Knowledge Level in Individuals Diagnosed with Inflammatory Bowel Disease (pre-test-post-test).

\begin{tabular}{|l|c|c|c|c|c|}
\hline & $\mathbf{N}$ & Minimum & Maximum & Mean & P \\
\hline Total score (pre-test) & 30 & 10 & 80 & 49.67 & $.071^{\star}$ \\
\hline Total score (post-test) & 30 & 40 & 100 & 72.67 & $0.128^{*}$ \\
\hline $\begin{array}{l}\text { Total score (first test) - Total score } \\
\text { (post test) analysis }\end{array}$ & & & & & $.000^{* *}$ \\
\hline
\end{tabular}

${ }^{\star}$ One-sample kolmogorov-smirnov test was used. ${ }^{* *}$ Paired samples test was used.

Table 5: First Test And Post Test Point Analysis Showing The Difference Between Sociodemographic Features And Drug Compliance.

\begin{tabular}{|c|c|c|}
\hline \multicolumn{2}{|c|}{ Sociodemographic Features } & \multirow{2}{*}{$\begin{array}{c}\text { Total Score (Post-Test) } \\
\text { Total Score (Pre-Test) (p) } \\
.002^{\star}\end{array}$} \\
\hline Gender & Female & \\
\hline & Male & $.003^{*}$ \\
\hline \multirow{2}{*}{ Marital status } & Married & $.000^{*}$ \\
\hline & Single & $.012^{*}$ \\
\hline \multirow{3}{*}{ Education Status } & Primary School Graduate & $.024^{*}$ \\
\hline & Secondary Education Graduate & $.006^{*}$ \\
\hline & Higher Education Graduate & $.011^{*}$ \\
\hline \multirow{2}{*}{ Economic Situation } & Income Equivalent to Expenses & $.001^{*}$ \\
\hline & Revenues Less Then Expenses & $.016^{*}$ \\
\hline \multirow{4}{*}{ Disease Duration } & Maximum 2 Years & $.223^{*}$ \\
\hline & 3-5 Years & $.039^{*}$ \\
\hline & 6-10 Years & $.027^{*}$ \\
\hline & More than 11 years & $.004^{*}$ \\
\hline \multirow{2}{*}{$\begin{array}{l}\text { Are there any people } \\
\text { who get support } \\
\text { because of your } \\
\text { illness? }\end{array}$} & Yes & $.004^{*}$ \\
\hline & No & $.001^{*}$ \\
\hline
\end{tabular}

*Wilcoxon marked rank test was used.

\section{Discussion}

When we evaluated the data in our study, we found that the preeducation means scores of the individuals with IBD who participated in the study were $\mathrm{x}=49.67$ after the education mean $\mathrm{x}=72.67$ (Table 4 ). Similarly, Nurit et al. (2009) found that patients who received training on their treatment showed higher compliance with the treatment after training [15]. The reason for the increase in the mean scores after the training, which we found in our study, may be the individual trainings planned with the prepared training booklet, videos, and slideshows after the patients have been correctly diagnosed. In some studies, it was found that compliance with treatment was higher in elderly patients than in younger patients $[16,17]$. This may be due to the increased use of medication due to older patients having more chronic diseases. However, in our study, we did not find a significant difference between treatment compliance and age (Table 4 ). $73.3 \%$ of individuals with IBD who participated in our study stated that they were most disturbed by the changes in the excretory habit due to the changes caused by the disease (Table 2). According to the data of N-ECCO (Nurse-European Crohn Colitis Association) (2013), it was stated that patients complain of the most intestinal control problems during hospitalization. It was determined that drug compliance of individuals with IBD who received nurse support for all other demographic 
features, except patients with a maximum disease duration of 2 years, was high. In patients with a maximum duration of 2 years, the effect of nurse support on drug compliance was found to be low. This result shows us that in patients newly diagnosed with IBD, nurse support is not effective on drug compliance. Similarly, Erci et al. (2018) found that in their study on hypertensive patients, compliance was lower in patients who had been diagnosed with hypertension for a year or less [18-20]. Based on these data, we comment on the process of accepting the disease of individuals who are new to chronic diseases and changing the behavior after getting the diagnosis of the disease.

\section{Conclusion}

In this study, it was observed that nurse support given to individuals with IBD in drug management increased the effectiveness of drug use.

\section{Disclosure}

There is no conflict of interest among the authors. In addition, our responsible company comes out with any company in the research.

\section{Ethical Aspect of the Research}

In order to conduct the research, the permission of the University's non-interventional research ethics board numbered E1700080677 and numbered 23.11 of 01.11 .2017 was obtained. Written and verbal consents of the patients who agreed to participate in the study were obtained. Research and publication ethics were followed at all stages of the article.

\section{Information}

Research idea, design, literature review, data analysis and review EÜA and DA; data collection was carried out by DA. No support was received from any project or firm related to the research. The budget of the research was covered by the researchers. There is no conflict of interest among the authors.

\section{References}

1. M O'Connor, P Bager, Duncan J, Gaarenstroom J, Younge L, et al. (2013) N-ECCO Consensus statements on the European nursing roles in caring for patients with Crohn's disease or ulcerative colitis. JCC 7: 744-764. [crossref]

2. Molodecky NA, Soon IS, Rabi DM, Ghali AW, Ferris M, et al. (2012) Increasing incidence and prevalence of the inflammatory bowel diseases with time, based on systematic review. Gastroenterology 142: 46-54. [crossref]

3. Mowat C, Cole A, Windsor A, Ahmad T, Arnott I, et al. (2011) IBD Section of the British Society of Gastroenterology. Guidelines for the management of inflammatory bowel disease in adults. Gut 60: 571-607.

4. Friedman SL, Mcquaid KR, Greendell JH. (eds) (2007) Current Diagnosis \& Treatment in Gastroenterology. Çev.Eds: Sivri B, Gönen Ö. Current. Gastroenterology Diagnosis and Treatment. Oncu Printing, İstanbul pg: 108-129.

5. Pithadia AB, Jain S (2011) Treatment of inflammatory bowel disease (IBD). Pharmacol Rep 63: 629-642.

6. Levine JS, Burakoff R (2011) Extraintestinal manifestations of inflammatory bowel disease. Gastroenterol Hepatol 7: 235-241. [crossref]

7. Golik M, Kurek M, Poteralska A, Bieniek E, Marynka A, et al. (2014) Working Group Guidelines on the nursing roles in caring for patients with Crohn's disease and ulcerative colitis in Poland. Prz Gastroenterol 9: 179-193. [crossref]

8. Ozgursoy Uran B, Yildırım Y (2016) A New specialty: inflammatory bowel disease nursing. İKÇÜSBFD. 1:27-33.
9. Green C, Elliott L, Beaudoin C, Bernstein CN (2006) A population-based ecologic study of inflammatory bowel disease: searching for etiologic clues. Am J Epidemiol 164: 615-628. [crossref]

10. Konduk BT, Gulsen MT (2017)When to start immunosuppressive therapy in inflammatory bowel diseases?. Current gastroenterology 21: 317-327. [crossref]

11. Stretton JG, Currie BK, Chauhan UK (2014) Inflammatory bowel disease nurses in Canada: an examination of Canadian gastroenterology nurses and their role in inflammatory bowel disease care. Can J Gastroenterol Hepatol 28: 89-93. [crossref]

12. Bernstein CN, Eliakim A, Fedail S, Fried M, Gearry R, et al. (2016) World Gastroenterology Organisation Global Guidelines Inflammatory Bowel Disease: Update August 2015. J Clin Gastroenterol 50: 803-818. [crossref]

13. Faust AH, Halpern LF, Danoff-Burg S, Cross RK (2012) Psychosocial factors contributing to inflammatory bowel disease activity and health-related quality of life. Gastroenterol Hepatol 8: 173-181. [crossref]

14. Leung WK (2015) Optimization of Inflammatory Bowel Disease Cohort Studies in Asia. Intest Res.;13: 208-212. [crossref]

15. Nurit P, Bella BC, Gila E, Revital Z (2009) Evaluation of a nursing intervention project to promote patient medication education. J Clin Nurs 18: 2530-2536. [crossref]

16. Altuntaş O, Akı E, Huri M (2015) A qualitative study on the effect of drug use on quality of life and social participation in chronic diseases. Journal of Occupational Therapy and Rehabilitation 3: 79-86. [crossref]

17. Gurol Arslan G, Eşer I. (2005) Yaşlıların kendi kendine ilaç kullanımına uyumu ve hemșirenin rolü. . EGEHFD. 21: 147-57.

18. Yılmaz F, Çolak MY (2018) Evaluation of drug faith and compliance to treatment in elderly individuals with chronic disease. Turkey Clinics J Health Sci 3: 113-121. [crossref]

19. Gokalp O, Mollaoğlu H (2003) Improper drug use. SDU Faculty of Medicine Journal 10:17-20.

20. Ercı B, Elıbol M, Akturk U (2018) Investigation of factors affecting hypertension patients' compliance to treatment and quality of life. FNJN 26: 79-92.
Citation:

Uysal DA, Avdal EU (2021) The Effect of Nursing Support on Drug Compliance in Inflammatory Bowel Diseases. Integr J Nurs Med Volume 2(3): 1-4. 